\title{
The biological function and clinical significance of SF3B1 mutations in cancer
}

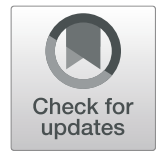

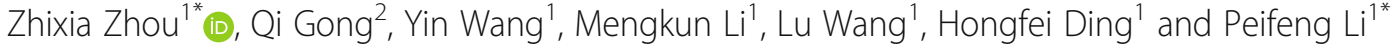

\begin{abstract}
Spliceosome mutations have become the most interesting mutations detected in human cancer in recent years. The spliceosome, a large, dynamic multimegadalton small nuclear ribonucleoprotein composed of small nuclear RNAs associated with proteins, is responsible for removing introns from precursor mRNA (premRNA) and generating mature, spliced mRNAs. SF3B1 is the largest subunit of the spliceosome factor 3b (SF3B) complex, which is a core component of spliceosomes. Recurrent somatic mutations in SF3B1 have been detected in human cancers, including hematological malignancies and solid tumors, and indicated to be related to patient prognosis. This review summarizes the research progress of SF3B1 mutations in cancer, including SF3B1 mutations in the HEAT domain, the multiple roles and aberrant splicing events of SF3B1 mutations in the pathogenesis of tumors, and changes in mutated cancer cells regarding sensitivity to SF3B small-molecule inhibitors. In addition, the potential of SF3B1 or its mutations to serve as biomarkers or therapeutic targets in cancer is discussed. The accumulated knowledge about SF3B1 mutations in cancer provides critical insight into the integral role the SF3B1 protein plays in mRNA splicing and suggests new targets for anticancer therapy.
\end{abstract}

Keywords: SF3B1, Mutation, Cancer, RNA splicing

\section{Background}

Of the 3.3 billion base pairs of haploid DNA in the human genome, approximately 20,000 protein-coding genes have been identified by the Encyclopedia of DNA Elements (ENCODE) project [1]. However, the number of protein-coding genes is surprisingly low given the proteomic complexity, as the number of protein isoforms expressed from this gene set has been estimated to be at least 5-10-fold higher [24]. The generation of protein diversity is primarily due to the process of precursor mRNA (premRNA) splicing, which is controlled by a complex regulatory system that consists of an enormous number of sequence elements and trans-acting splicing factors; therefore, it is not surprising that the mRNA splicing machinery is susceptible to mutations and that these mutations are implicated in many

\footnotetext{
*Correspondence: zhou_zhixia@qdu.edu.cn; peifeng@ioz.ac.cn ${ }^{1}$ Institute for Translational Medicine, The Affiliated Hospital of Qingdao University, College of Medicine, Qingdao University, Qingdao 266012, People's Republic of China

Full list of author information is available at the end of the article
}

human diseases, including cancer $[5,6]$. Indeed, genomewide studies have revealed more than 15,000 tumorassociated splice variants in a wide variety of cancers $[7,8]$.

Recently, the most interesting mutations detected in human cancer were found to target components of the spliceosome involved in the mRNA-splicing process, as indicated by genomic DNA analysis of a variety of human tumors studied through the Cancer Genome Project. One of the most exciting discoveries has been recurring somatic mutations in genes encoding 3 splicesite recognition protein components and serine/arginine-rich (SR) splicing factors, which were initially discovered in myelodysplastic syndrome (MDS) in 2011 and later reported in other hematological malignancies, including solid tumors [9-13]. Spliceosome mutations in cancers have highlighted the importance of the spliceosome pathway as a direct player in carcinogenesis and led to questions regarding the functional roles and molecular mechanisms of these mutations [14]. 
In this review, we describe spliceosome-associated transcript processing and its impact on disease. Moreover, we focus on one of the frequently mutated spliceosome proteins: cancer-related splicing factor $3 \mathrm{~b}$ subunit 1 (SF3B1). We mainly summarize the distribution of mutations in SF3B1, mutant expression in tumors and its prognostic value. In particular, we discuss the functional consequences of SF3B1 mutation in tumors, with multiple roles in tumor pathogenesis, aberrant splicing events, and changes in sensitivity to SF3B smallmolecule inhibitors. The potential value of $S F 3 B 1$ or its mutation as a novel cancer therapeutic target and marker that is more sensitive to spliceosome inhibitors is also described. Finally, we explore the options available for future research on the biological function and clinical significance of SF3B1 mutations in cancer.

\section{Precursor mRNA (premRNA) splicing}

Precursor mRNA splicing is an essential step in the posttranscriptional regulation of gene expression and is a process that involves the removal of noncoding sequences (introns) from premRNA and the ligation of coding sequences (exons) to form mRNA. PremRNA splicing is catalyzed by the spliceosome, a complex consisting of 5 small nuclear RNAs (snRNAs) that associate with proteins to form particles termed small nuclear ribonucleoproteins (snRNPs) [15-17]. To date, two types of spliceosomes with unique compositions have been characterized: U2-dependent (major) spliceosomes and U12-dependent (minor) spliceosomes. The former spliceosome has been found in all eukaryotes and consists of the U1, U2, U5, and U4/U6 snRNPs and numerous proteins. Each U1, U2, and U5 snRNP has a single snRNA and several proteins; the U4 and U6 snRNPs have 2 snRNAs and several proteins. This spliceosome catalyzes the vast majority of transcript splicing events, removing the most commonly encountered class of introns (U2-type introns) (more than 99\% in humans) $[18,19]$. In contrast, the U12-dependent spliceosome is found only in a number of organisms, and acts on U12-type introns (less than $1 \%$ of introns in humans) [20,21]. The difference between U2-type and U12-type introns is in the consensus splicesite sequence. The U12-dependent spliceosome also consists of 5 snRNPs, U11, U12, U5, and U4atac/U6atac snRNPs [22, 23].

The stepwise interactions between premRNA and both U2- and U12-dependent spliceosome snRNPs are highly ordered, as shown in Fig. 1. Briefly, assembly of the U2dependent spliceosome is initiated by interaction of the U1 snRNP with the $5^{\prime}$ splice site, which includes a GU, leading to the formation of the E complex. Then, the U2 snRNP binds to the branch site (BS) to generate the A complex or the prespliceosome. When the U5 and U4/ U6 snRNPs interact with the A complex, the B complex is generated. U4/U6 base-pairing interaction is disrupted, and U6 displaces U1 snRNA, which then binds to the $5^{\prime}$ splice site. After B complex rearrangement, a catalytically active $B^{*}$ complex is produced through U1 and U4 snRNP dissociation. The mRNA is released after completion of the first (the $\mathrm{C}$ complex is formed) and second catalytic steps of splicing, in which the intron is removed, and the spliceosome dissociates to be recycled

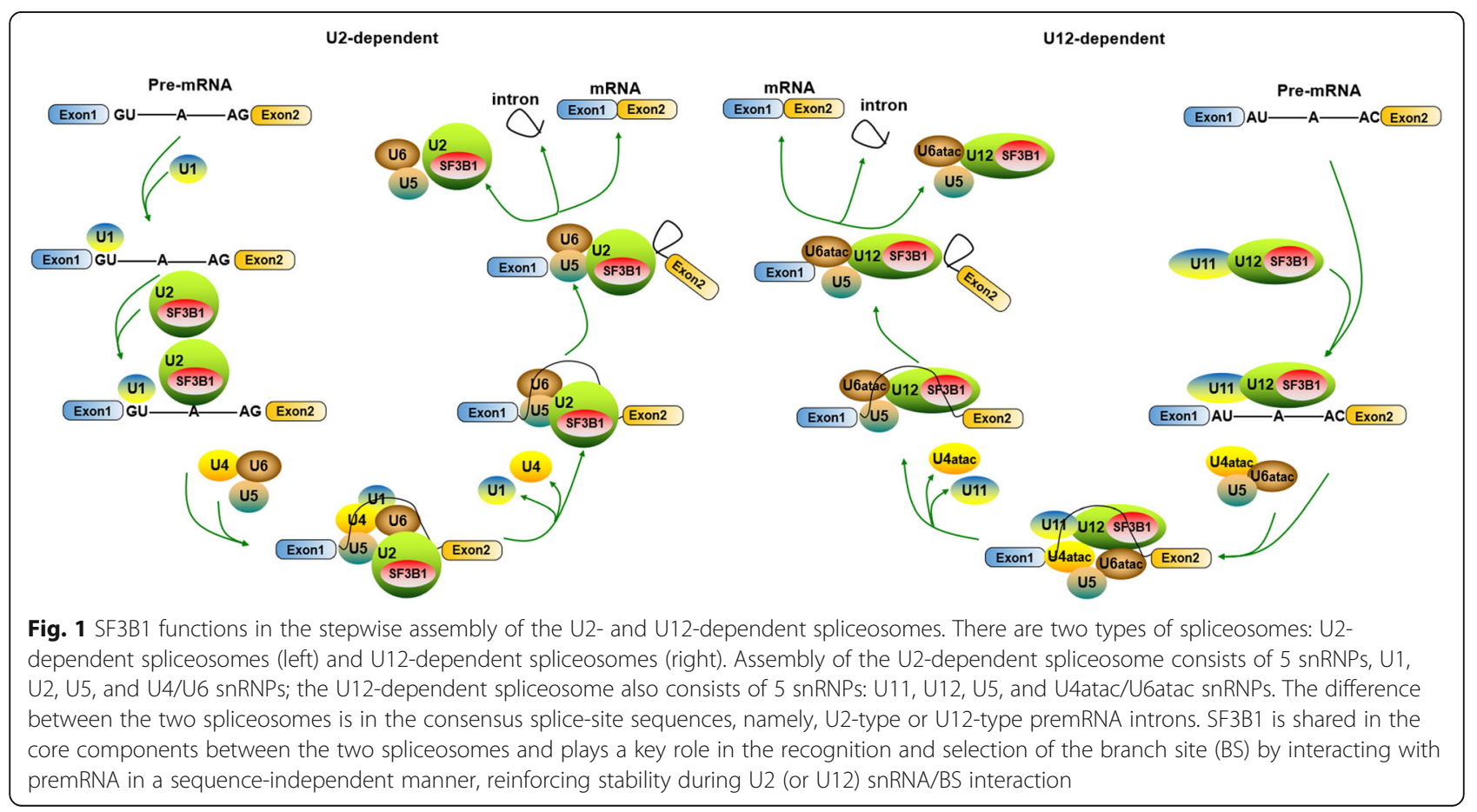


for new premRNA splicing [24, 25]. Assembly of the U12dependent spliceosome is similar to that of the U2dependent spliceosome because U11, U12 and U4atac/ U6atac snRNPs are functional analogs of the snRNPs U1, $\mathrm{U} 2$ and U4/U6. U12-dependent spliceosome assembly also involves sequential formation of the $\mathrm{A}, \mathrm{B}, \mathrm{B}$, and $\mathrm{C}$ complexes, but the earliest $\mathrm{E}$ complex formation step does not occur $[21,23]$. The differences in the premRNA splicing mechanism mediated by the U2- and U12-dependent spliceosomes appear to involve only early intron recognition events and not the catalytic process.

A large, diverse and dynamic protein has been found that interacts with snRNAs to form snRNPs within the spliceosome. Although the U2- and U12-dependent spliceosomes differ in their snRNA composition, they share many proteins [26-29]. For example, all of the subunits of the protein complex SF3B, namely, SF3B155/SF3B1, SF3B145, SF3B130, SF3B49, SF3B14a/p14, SF3B14b and SF3B10, are the same [30]. SF3B contributes a molecular mass of $\sim 450 \mathrm{kDa}$ to each snRNP, and it has been demonstrated to play a key role in the recognition and selection of the branch site (BS) during splicing by interacting with the premRNA at or near the BS in a sequence-independent manner, reinforcing stability during the U2 snRNA/BS interaction [31]. In addition, numerous splicing factors, including an array of regulatory elements and proteins, participate in premRNA splicing events involving the two types of spliceosomes, such as exonic splicing enhancer (ESE), exonic splicing silencer (ESS), intronic splicing enhancer (ISE), intronic splicing silencer (ISS), SR proteins, heterogeneous nuclear ribonucleoproteins (hnRNPs), and others [5, 17, 32-34]. Thus, although premRNA splicing is traditionally considered to involve separate and sequential processes, it is difficult for spliceosomes and associated proteins to detect specific splice sites in a vast RNA pool. This complexity makes the premRNA splicing machinery susceptible to sequence polymorphisms and deleterious mutations, some of which eventually lead to diseases, the number of which is growing [5]. Therefore, some specific mutations or polymorphisms of premRNA splicing factors have become important diagnostic markers and therapeutic targets in human diseases.

\section{Alternative splicing}

Two different modes of splicing have been defined: constitutive splicing and alternative splicing. Constitutive splicing is the process of removing introns from premRNA and joining the exons together to form a mature mRNA sequence. Alternative splicing is the process by which the exons are either retained or targeted for removal in different combinations to yield a diverse array of mRNAs from a single premRNA [35]. There are several distinct patterns of alternative splicing, including cassette exons (in which one or more exons are either skipped or included), alternative $5^{\prime}$ splice sites, intron retention, mutually exclusive exons, alternative 3 ' splice sites, and complex splicing patterns [36]. More than $90 \%$ of human genes produce transcripts that are alternatively spliced, and $60 \%$ of the splice variants encode distinct protein isoforms with unique cellular functions or properties [37-39]. Thus, alternative splicing plays important biological roles in the proliferation, differentiation and/or development of cells. In humans, the regulation of alternative splicing is tightly controlled during normal biological events [40]. Misregulation of alternative splicing can lead to the production of aberrant protein isoforms, which may contribute to serious diseases, including cancers. Thus, an in-depth investigation of alternative splicing regulation has become the trend to understand the mechanisms of human diseases.

\section{Splicing mutations in human disease}

Disease-related mutations can affect splicing by altering splice site sequences, splicing regulatory sequences, or genes of the splicing machinery itself (i.e., spliceosome mutations) [41, 42], and mutations of the splice-site sequences or of the splicing regulatory sequences have been documented in a variety of human diseases. For example, mutations in the splice-site sequences of the $H B B$ (hemoglobin, beta) gene lead to abnormal splicing of $H B B$ and defective synthesis of its protein $\beta$-globin in human $\beta^{+}$-thalassemia [43-45]. In human multisystem proteinopathy and amyotrophic lateral sclerosis (ALS), mutations in the prion-like domains of hnRNPA2B1 and hnRNPA1 occur [46]. An array of mutations in splicing cis-acting sequences include those of $L K B 1$ (liver kinase B1), KIT (v-kit Hardy-Zuckerman 4 feline sarcoma viral oncogene homolog), CDH17 (cadherin 17), KLF6 (Kruppel-like factor 6) and BRCA1 (breast cancer gene 1) in many types of cancers $[47,48]$.

In addition to mutations that alter precursor RNA sequence elements that regulate splicing, components of the spliceosome machinery have been shown to be dysregulated in human disease. An example discovered relatively early is that mutations in tri-snRNP (small ribonucleoprotein), a preassembled complex of $\mathrm{U} 4$ snRNA hybridized to U6 (U4/U6 or U4atac/U6atac) that also contains U5 (U4/U6 or U5) and associated proteins, can cause an autosomal dominant form of retinitis pigmentosa (adRP) [6, 34]. Since 2011, recurrent somatic mutations have been identified in a number of spliceosome components in human malignancies through the Cancer Genome Project, such as U2AF1 (U2AF35), SRSF2 (SC35), SF3B1 (SF3B155 or SAP155), and ZRSR2 (URP) [13]. These spliceosome component mutations indicates somatic mutations are an important molecular mechanism underlying splicing deregulation in diseases. 
In this review, we discuss recently discovered examples of disease-linked spliceosome mutations in SF3B1 that are shared in the core comments between the two spliceosomes (Fig. 1).

\section{SF3B1 mutations in cancer}

Distribution of mutations in the molecular architecture of SF3B1

SF3B1 (splicing factor $3 \mathrm{~b}$ subunit 1 ) is the largest subunit of the SF3B complex and functions by serving as a core component of the U2 snRNP, which is critical for branch site recognition and for the early stages of spliceosome assembly [49]. Structurally, the N-terminal hydrophilic region of SF3B1 has multiple U2AF2 binding motifs $[50,51]$, which may facilitate localization of the U2 snRNP to the vicinity of the branch site. Two-thirds of the C-terminus consists of 22 nonidentical HEAT (Huntingtin, elongation factor 3 , subunit An of protein phosphatase 2A, and phosphatidylinositol 3-kinase (PI3K) target of rapamycin 1) repeats, which form rodlike helical structures, providing major scaffolding for the U2 snRNP to support interactions with other SF3B subunits, including p14 [52]. The HEAT-repeat superhelix of SF3B1 defines a composite RNA-binding platform for BS recognition. In human diseases, almost all mutations in SF3B1 are located in the HEAT domain, particularly from $\mathrm{H} 4-\mathrm{H} 12$, as shown in Fig. 2. Among the mutated codons, 700 account for more than $50 \%$ of the variants observed, and additional codons $(666,662$, 622 , and 625 ) have been found to be hotspots for mutation $[41,53-55]$.

\section{Mutant SF3B1 expression in cancer}

Mutations in SF3B1 have been implicated as common drivers of hematologic malignancies. Somatic SF3B1 mutations are found in approximately $30 \%$ of patients with MDS and as many as $80 \%$ of patients with the MDS subtype characterized by ring sideroblasts (MDS-RARS) [41, $56,57]$. These mutations are also present in $20 \%$ of patients with myelodysplastic/myeloproliferative neoplasm (MDS/MPN) [41] and in 15\% of patients with chronic myeloid leukemia (CLL) [58-60]. More recently, SF3B1 mutations have been identified at relatively high frequency in some solid tumors, such as various pigmented tumors, including uveal melanoma (UM) [61, 62], mucosal melanoma [63], leptomeningeal melanoma [64] and blue nevus-like cutaneous melanoma [65], and neuroblastomas that arise following chromothripsis [66], estrogen receptor-positive breast cancers (BC) [67], pancreatic ductal adenocarcinoma [68], prostate cancer [69], prolactinomas [70], acute myeloid leukemia [71, 72], and many others [73-75].

\section{Prognostic value of SF3B1 mutation in cancer}

The prognostic value of the SF3B1 mutation in MDS remains controversial. Most studies have claimed that patients carrying an SF3B1 mutation have a significantly better overall survival and a lower likelihood of their disease transforming into acute leukemia compared with patients without SF3B1 mutations [11, 41, 76, 77]. In contrast, some studies found no significant effect of mutation on clinical outcomes [78, 79]. Regardless, SF3B1 appears to be the only gene for which somatic mutations are associated with a good prognosis in MDS [41, 80]. As with MDS, SF3B1 mutations were found to confer a favorable prognosis in uveal melanoma (UM), with a younger age of onset and concurrent disomy 3 [81, 82]. In addition, patients with SF3B1-mutated UM had better survival (at 5 years) than did SF3B1 wild-type patients. Nonetheless, evidence also shows that the survival differences between patients with SF3B1-mutant tumors and SF3B1 wild-type tumors are not significant over time, as indicated by follow-up data (at 10 years). Moreover, SF3B1-mutant UM is reported to cause late metastasis (median 8.2 years after initial diagnosis), suggesting that patients with SF3B1 mutations are also at risk for metastasis, particularly late-onset metastasis [83]. It was inferred that the positive prognostic value of SF3B1 mutation may be partly or completely lost after the acquisition of other gene mutations associated with disease progression [41]. In contrast to those in MDS or UM, SF3B1 mutations that are cancer-related occur more commonly in advanced disease and tend to be associated with poor prognosis in other malignancies, including

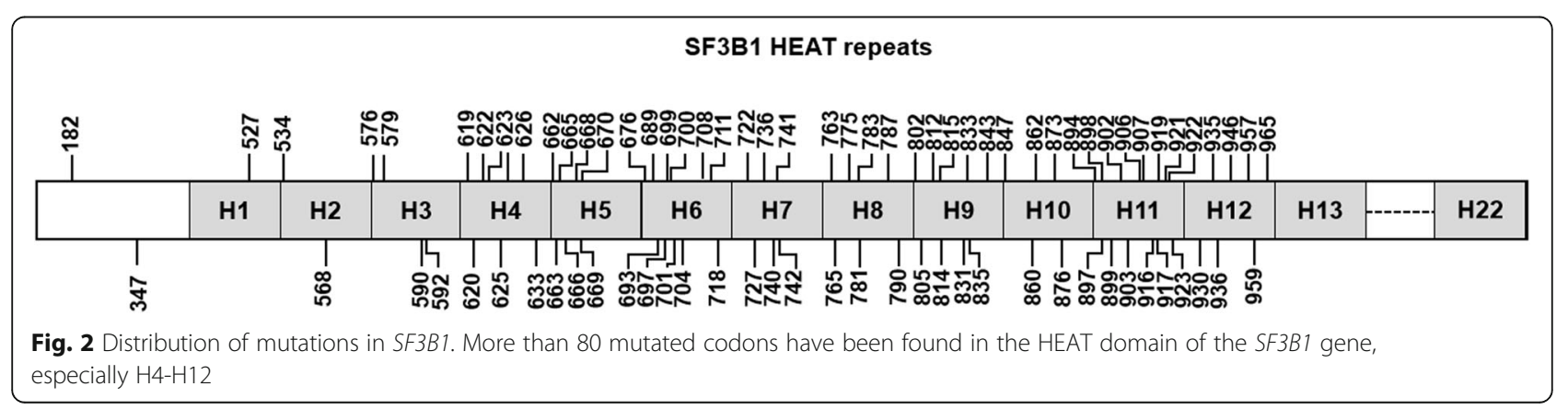


CLL. Thus, the prognostic relevance of SF3B1 mutations in disease may be dependent on cellular contexts.

\section{Functional consequences of SF3B1 mutation in cancer \\ Multiple roles in tumor pathogenesis}

To date, it remains unclear what functional role SF3B1 mutations play in carcinogenesis, and it has not been well established whether deregulated SF3B1 activity is required for the maintenance of cancer [84]. To address these questions, the role of $S F 3 B 1$ mutations in malignant hematopoiesis has been investigated in vitro and in vivo. Regarding MDS, an $S F 3 B 1^{K 700 E}$ conditional knock-in mouse has been generated [85], and heterozygous expression of $S F 3 B 1^{K 700 E}$ caused progressive macrocytic anemia [85]. Moreover, $S F 3 B 1^{\mathrm{K} 700 \mathrm{E}}$ expression was associated with aberrant 3' splice-site selection as well as increased nonsense-mediated decay [85]. In another study, conditional SF3B $1^{f l o x-K 700 E /+}$ mice were generated by targeted modification of the SF3B1 locus in JM8 mouse embryonic stem cells (ESCs). SF3B1 $1^{\text {K7OOE/+ }}$ mice develop progressive normocytic anemia without ring sideroblasts [86]. In addition to erythropoiesis, $S F 3 B 1^{K 700 E /+}$ mice had reduced numbers of hematopoietic stem cells (HSCs) and exhibited a myeloid cell bias [86]. Furthermore, the self-renewal potential of $S F 3 B 1^{K 700 E /+}$ HSCs was determined by their repopulating ability in competitive transplantation assays into either young or old recipient mice. The results revealed a fitness disadvantage of mutant over wild-type HSCs [86], which contrasts with observations that mutant SF3B1 drives clonal hematopoiesis and may even be the sole identifiable driver mutation in human MDS $[87,88]$. In addition, simultaneous expression of SF3B1 and SRSF2 mutations in mice resulted in increased apoptosis and reduced quiescence of hematopoietic stem progenitor cells (HSPCs). Moreover, combined expression of SF3B1 and SRSF2 mutations impaired expression of regulators of HSPC survival and increased sensitivity to inflammatory stimulation [89]. In human SF3B1-mutated CLL cases, ATM kinase function remained intact, and $\gamma \mathrm{H} 2 \mathrm{AX}$ formation, a marker for DNA damage, was found to be increased at baseline and upon irradiation, demonstrating that mutations in SF3B1 are associated with increased DNA damage and/or an aberrant response to DNA damage [90]. In many cancer cells, SF3B1 mutation was found to dysregulate multiple cellular functions, including heme biosynthesis, immune infiltration, DNA damage response, R-loop formation, telomere maintenance, and Notch signaling [74, 91-93], as well as many cellular pathways, such as the mitochondrial, Notch and NF- $k B$ pathways [91]. These results suggest that $S F 3 B 1$ mutations play multiple roles in the pathogenesis of tumors.

\section{Aberrant splicing events}

In terms of SF3B1 as a core component of splicing machinery, it has been clearly proven that common and tumor-specific splicing aberrations are induced by SF3B1 mutations, and aberrant 3 ' ss selection has been established as the most frequent splicing defect [94], with increased alternative 3 ' splice site usage [85] and usage of cryptic $3^{\prime}$ splice sites [86], as shown in Fig. 3. Strikingly, SF3B1 variants utilize a BPS that differs from that used by wild-type SF3B1 and requires the canonical $3^{\prime}$ ss to enable aberrant splicing during the second step [94]. SF3B1 mutations result in neomorphic activity, causing hundreds of alterations both through aberrant splicing and dysregulated gene expression in common alternative splicing signatures in different types of cancers [95]. Furthermore, SF3B1 mutations are linked to various RNA processing mechanisms, such as alternative terminal exons, alternative 3 ' acceptor splice sites, alternative cassette exons, alternative first exon, alternative branch point usage, and intron retention [96, 97]. Approximately $50 \%$ of aberrantly spliced mRNAs are subjected to nonsense-mediated decay, resulting in downregulation of gene and protein expression [94, 98]. However, few of these genes have been functionally implicated in driving the diseases known to be associated with SF3B1 mutations, including the genes shown in Fig. 4. Thus, the functional consequences and mechanisms of SF3B1 mutations in cancers need to be further investigated.

\section{Associations between aberrant splicing and clinical variables or patient survival}

Fifteen aberrant splicing (PARVG, RPRD1A, DOM3Z, CXXC1, AP1G2, SNRPN, TCEA2, NICN1, ABCC5, ERCC3, SNRPN, PPOX, GPR108, PSTPIP1, NICN1) events have been correlated with clinical variables that showed a significant difference between $S F 3 B 1^{\text {mut }}$ and SF3B1 ${ }^{\text {wt }}$ patients with MDS, including a lower percentage of bone marrow (BM) blasts and higher number of white blood cells, absolute neutrophil count (ANC), and platelet count (Plt) in the $S F 3 B 1^{\text {mut }}$ group [92]. Moreover, isoform expression of extracellular exosome/focal adhesion genes (CRTC2, PPOX, AHSA2, DHP5) produced by aberrant splicing events in $S F 3 B 1^{\text {mut }}$ patients has been identified as a significant survival predictor in MDS [92, 99]. The functions of eight genes (BRD9, SUGP1, MAP3K7, TERC, KLF8, DVL2, SEPT2, and $A B C B 7)$ with deregulated expression due to $S F 3 B 1 \mathrm{mu}$ tations in tumors are discussed below.

\section{BRD9}

Homo sapiens bromodomain containing (BRD) 9 is a core component of the recently described mammalian BRG1-associated factor (BAF) chromatin remodeling 

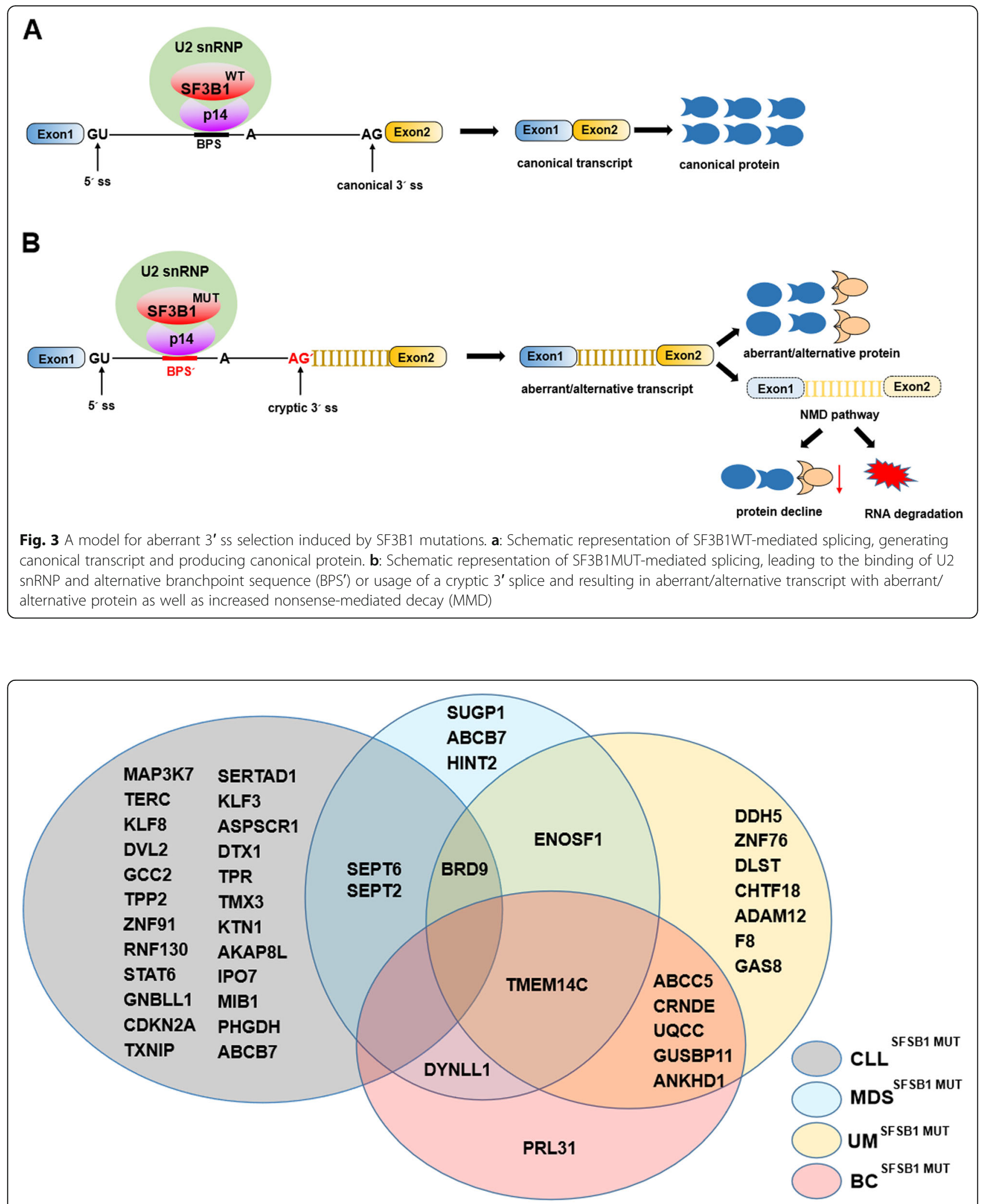

Fig. 4 Venn diagrams showing SF3B1 mutation-associated aberrant splicing genes identified by RNAseq and validated by qRT-PCR in CLL, MDS, $U M$, and $B C$. At least 46 genes are produced by aberrant splicing events in SF3B1 ${ }^{\text {mut }} C L L, M D S, U M$, and $B C$. Among them, BRD9 is shared by CLL, MDS and UM and TMEM14C by MDS, UM and BC. SEPT6 and SEPT2 are shared by CLL and MDS, ENOSF1 by MDS and UM, and DYNLL1 by MDS and $B C$ 
complex that plays an important role in maintaining the transcriptional network of pluripotency [100]. Previous studies have reported that BRD9 is required for the survival of some cancer types, particularly cancers with mutations that affect polybromo-associated BAF and canonical BAF6 [101-103]. Recently, it was found that total levels of $B R D 9$ mRNA were reduced in patients with CLL, MDS and UM carrying SF3B1 mutation. Further study found that mutant SF3B1 suppressed levels of full-length BRD9 protein without generating a truncated BRD9 protein in UM (MEL270) or myeloid leukemia (K562) cells that express SF3B1 ${ }^{K 700 E}$. Mutant SF3B1 recognizes an aberrant, deep intronic branch point within $B R D 9$ and thereby induces the inclusion of a poison exon that is derived from an endogenous retroviral element, causing subsequent degradation of $B R D 9$ mRNA. Depletion of BRD9 in turn causes loss of noncanonical BAF at CTCF-associated loci, resulting in alteration of BAF localization to chromatin. BRD9 loss may also alter the expression of distinct genes involved in apoptosis and cell growth, adhesion and migration. In addition, it was also found that disruption of ncBAFdependent regulation of HTRA1 (HtrA serine peptidase 1) contributes to the protumorigenic effects of $B R D 9$ loss. Correcting misspliced BRD9 in SF3B1-mutant cells using antisense oligonucleotides or CRISPR-directed mutagenesis suppresses tumor growth [100]. These results implicate the disruption of noncanonical BAF in the diverse cancer types associated with SF3B1 mutations and suggest a mechanism-based therapeutic approach for treating these malignancies [104].

\section{SUGP1}

SUGP1 (SURP And G-patch domain-containing protein, a member of the SURP family of splicing factors that likely interact with SF1 and RNA helicases) is also greatly reduced in samples from MDS patient harboring SF3B1 mutation [53, 105-107]. Furthermore, loss or weakening of the interaction of SUGP1 with SF3B1 in the spliceosome was found to be the sole cause of defects in BP recognition, which results in the use of cryptic $3^{\prime}$ ss typically located 10-30 nt upstream of canonical 3 ' ss [53]. That is, under normal conditions, the WT SF3B1 spliceosome uses a canonical BP and 30'ss for splicing; when the interaction between SF3B1 and SUGP1 is disrupted by SF3B1 mutations, the mutant SF3B1 spliceosome uses an upstream BP and a cryptic $30^{\prime}$ ss for splicing. Furthermore, SUGP1 can associate with the mutant spliceosome and partially rescue splicing defects [53]. These data suggest that loss of SUGP1 is a common defect in spliceosomes with cancerassociated SF3B1 mutations and that the mutant spliceosome is "repairable" in principle via restoration of SUGP1 assembly [108].

\section{MAP3K7}

MAP3K7 (mitogen-activated protein kinase kinase kinase 7) encodes a kinase that mediates tumor necrosis factor $\alpha(\mathrm{TNF} \alpha)$, interleukin-1 $\beta$ (IL-1 $\beta)$, and Toll-like receptor signaling through the NF- $\mathrm{kB}$, JNK, and MAPK pathways. Loss of MAP $3 K 7$ results in the attenuation or promotion of inflammation, depending on the cellular context [109-111]. Reduced MAP3K7 mRNA and protein are both found in isogenic cell lines and primary myeloid and lymphoid cells from MDS and CLL patients carrying SF3B1 mutations [89]. In contrast, hyperactive NF- $\kappa B$ signaling with increasing p-p65 levels is detected in $S F 3 B 1^{K 700 E}$ human myeloid and lymphoid leukemia cells stimulated with LPS. Re-expression of MAP3K7 in $S F 3 B 1^{K 700 E}$ cells leads to a significant decrease in p-p65 in both the resting state and following LPS exposure. Additionally, restoration of MAP3K7 expression in $S F 3 B 1^{K 700 E}$ cells results in partial rescue of cell clonogenicity [89]. These data suggest that $S F 3 B 1$ mutations affect the splicing of $M A P 3 K 7$, which, at least in part, the results in hyperactivation of NF-KB signaling, which is associated with MDS pathogenesis.

\section{TERC}

TERC (telomerase RNA component), encoding an essential RNA component of telomeres, plays a role in cell proliferative potential, telomerase activity and telomere length, and TERC mutations have been found in autosomal dominant dyskeratosis congenita (DC), aplastic anemia, MDS, and cervical cancer [112-115]. TERC is a noteworthy target with significantly increased expression in SF3B1-mutated CLL samples, as based on amplification using total RNA [91]. Upregulation of TERC and TERT (telomerase reverse transcriptase) was confirmed in Nalm6 isogenic cell lines with K700E and H622Q mutations. Not surprisingly, higher telomerase activity was detected in Nalm-6 SF3B1 $1^{\text {KTOOE }}$ cells than in wild-type cell lines. These data suggest that mutant SF3B1 may affect telomerase activity through dysregulation of TERC and TERT expression [91].

\section{KLF8}

KLF8 (Kruppel-like transcription factor 8) has been found to be involved in tumor cell proliferation, transformation, and progression and in DNA damage repair in several different tumors, including renal cell carcinoma, hepatocellular carcinoma and breast cancer [116]. KLF8 is consistently upregulated in SF3B1-mutated CLL samples at both single-cell and bulk RNA levels. Overexpression of SF3B1 in cells induces phosphorylation of H2AX ( $\gamma \mathrm{H} 2 \mathrm{AX})[90,91]$ and CHK2 (checkpoint kinase 2) [91], two markers of DNA damage, following exposure to gamma irradiation. These data demonstrate that single mutations in SF3B1 are associated with increased 
DNA damage and/or an aberrant response to DNA damage and that SF3B1 mutation-associated gene dysregulation is a contributor to altered DNA responses $[90,91]$.

\section{DVL2}

Dishevelled 2 (DVL2) has been previously reported to play a role in both canonical and noncanonical Wnt signaling by binding to the cytoplasmic C-terminus of frizzled family members and inducing transduction of the Wnt signal to downstream effectors [117, 118]. Relatively high expression of the $D V L 2$ splice variant and the protein product of altered $D V L 2$ have been confirmed in individual primary CLL cells with SF3B1 mutation [91]. Interestingly, altering $D V L 2$ does not influence Wnt signaling, but it does affect the Notch pathway: expression of altered DVL2 markedly abrogates the activation of Notch1 and expression of the Notch pathway target gene HES1 (hairy and enhancer of split-1). Moreover, combined expression of WT and altered DVL2 reverses these suppressive effects, suggesting a dominant impact of altered DVL2 on the WT isoform [91]. These data implicate DVL2 as a target of mutated SF3B1 through which alternative splicing modulates Notch signaling activity.

\section{SEPT2}

SEPT2 (septin 2), a member of the septin family of guanosine triphosphatases, plays a role in the biogenesis of polarized columnar-shaped epithelium by maintaining polyglutamylated microtubules and an important role in the regulation of mitosis and cell growth $[119,120]$. SEPT2 is significantly downregulated in $\mathrm{CD}^{+} 4^{+}$cells with SF3B1 mutations in patients with MDS [92]. In addition, the effect of SEPT2 silencing on erythroid cell growth and differentiation has been studied in human $\mathrm{BM} \mathrm{CD} 34^{+}$cells. It was found that SEPT2 silencing leads to significantly impaired growth, G1/S transition arrest and a significant decrease in intermediate and late erythroid cell populations [92]. These results suggest that aberrant splicing of SEPT2 may lead to impaired erythropoiesis in association with SF3B1 mutations in patients with MDS.

\section{$A B C B 7$}

ABCB7 (ATP binding cassette subfamily B member 7) encodes a half-transporter involved in the transport of heme from the mitochondria to the cytosol and plays a role in mitochondrial iron accumulation, isodicentric chromosome formation (X)(q13) and sideroblastic anemia, which is involved in many hematologic malignancies [121-123]. Aberrant splicing of ABCB7 occurs in MDS RARS and SF3B1 $1^{\text {mut }}$ MDS patients and significant ABCB7 downregulation in $S F 3 B 1^{\text {mut }}$ cases $[92,96]$. In normal bone marrow, $A B C B 7$ downregulation reduces erythroid differentiation, growth and colony formation and results in a gene expression pattern similar to that observed in intermediate MDS-RARS erythroblasts and in the accumulation of FTMT. Moreover, silencing SF3B1 results in downregulation of $A B C B 7$ in K562 cells undergoing erythroid differentiation, implicating $A B C B 7$ in the acquisition of the RARS phenotype [124]. Furthermore, an $A B C B 7$ cryptic 3 ' splice site event was detected in SF3B1-mutant HSCs carrying the $S F 3 B 1^{K 700 E}$ mutation; nonsense-mediated RNA decay (NMD) can target the aberrantly spliced $A B C B 7$ transcript and underlies the downregulation of $A B C B 7 \mathrm{ob}-$ served in MDS patients with SF3B1 mutation. Moreover, treatment of $S F 3 B 1^{K 700 E}$-mutant cells with cycloheximide resulted in an increase in the aberrantly spliced form of the $A B C B 7$ transcript [96]. Interestingly, the sequence of the $A B C B 7$ cryptic ss is not conserved in mice, and there is no aberrant splicing of $A B C B 7$ in SF3B1-mutant murine cells $[85,86]$, which indicates significant differences in the transcripts affected because of $S F 3 B 1^{K 70 O E}$ between humans and mice. These data provide strong evidence that $S F 3 B 1$ mutation leads to aberrant $A B C B 7$ splicing and downregulation via NMD in human cancer cells and suggest an ABCB7-based therapeutic approach for treating these malignancies.

In addition, the roles and mechanisms of many other key cancer-related genes that have been detected by RNA sequencing and validated by qRT-PCR in distinct types of cancer need to be further investigated, such as TMEM14C (transmembrane protein 14C), SEPT6 (septin 6), and ENOSF1 (enolase superfamily member 1), as shown in Fig. 4. More genes that can be categorized into one of two large groups, a cell-autonomous gene set and a set of genes in immune cells with signatures related to immune cell infiltration, need to be confirmed in vitro and in vivo [74].

\section{Changes in sensitivity to SF3B small-molecule inhibitors}

Because the spliceosome SF3B complex has emerged as a potential therapeutic target, SF3B small-molecule inhibitors are currently under development and have entered clinical trials [125-127]. These inhibitors specifically target the SF3B protein complex, leading to the loss of spliceosome function with regard to 3 splice site recognition and resulting in aberrant alternative splicing/mRNA transport. Among them, three bacterial fermentation products (FR901464, herboxidiene, and pladienolide) were identified as natural compounds with antitumorigenic properties [126]. In addition to natural drugs, meayamycin, E7107, and spliceostatin A (SSA) have been developed as synthetic analogs with improved stability and solubility [58]. Among them, pladienolide (Pla) stalls SF3B in an open conformation by acting like a wedge within a hinge, modulating the 
transition of SF3B to the closed conformation needed to form the BS adenosine-binding pocket and stably accommodate the BS/U2 duplex [128, 129]. Although Pla$B$ might be located in the vicinity of both SF3B1 and SF3B3, it only binds to SF3B3 [130]. Additionally, E7107, a synthetic derivative of pladienolide $\mathrm{D}$, and SSA, a methylated derivative antitumor natural product FR901464, mainly destabilize U2 snRNP assembly at 3' splice sites by blocking SF3B from binding to RNA [126]. E7107 targets SF3B1 to block ATP-dependent A complex formation as well as a conformational change in U2 that exposes the snRNA region responsible for base pairing to the branchpoint sequence [131], whereas SSA induces a conformational shift in the U2 snRNP to bind to "decoy" sequences that can occur upstream of the branchpoint sequence [58].

Interestingly, one disease-associated SF3B1 mutation has the opposite effects on sensitivity to SF3B smallmolecule inhibitors, as shown in Fig. 5. An R1074H mutation in SF3B1 confers resistance to pladienolide activity by impairing the ability of pladienolide $\mathrm{B}$ to bind to SF3B due to the physical interference caused by $S F 3 B 1$ mutation [132], and it was speculated that SF3B1 mutations in other HEAT repeats might have the same effect [58]. These data indicate that the mutant SF3B1 protein has an impaired response to pladienolide B. In contrast to pladienolide B, it was reported that the $S F 3 B 1$ mutant cell lines Panc 05.04 (pancreatic, K700E) and ESS-1 (endometrial, K666N) were more sensitive to SAA, leading to inhibition of cell growth [133]. In contrast to SF $3 B 1^{+/+}$murine HSPCs, SF $3 B 1^{+/ K 700 E}$ HSPCs were more sensitive to the spliceosome modulator E7107E [85]. Furthermore, treatment of $S F 3 B 1^{+/ K 700 E}$ recipients with E7107 in vivo caused a significant decrease in CD45.2 chimerism in the peripheral blood, bone marrow, and spleen [85]. These data demonstrate that SF3B1 mutation enhances the sensitivity of tumor cells to the spliceosome modulator E7107 and SAA but not pladienolide B. SF3B1 mutation therefore sensitizes cells to pharmacologic targeting of wild-type SF3B1, consistent with the observation that the growth of SF3B1-mutant endometrial cancer and uveal melanoma cell lines was impaired by deletion of wild-type, but not mutant, SF3B1 [84]. Although the mechanism of the enhancement sensitivity to splicing inhibitors is unknown, probably because a mutated SF3B1 gene may be unable to tolerate further perturbations in splicing and therefore be preferentially sensitive to pharmacological splicing inhibition [134], these findings suggest that there may be a therapeutic window for the use of spliceosome modulators in the treatment of hematologic malignancies with SF3B1 mutation [85].

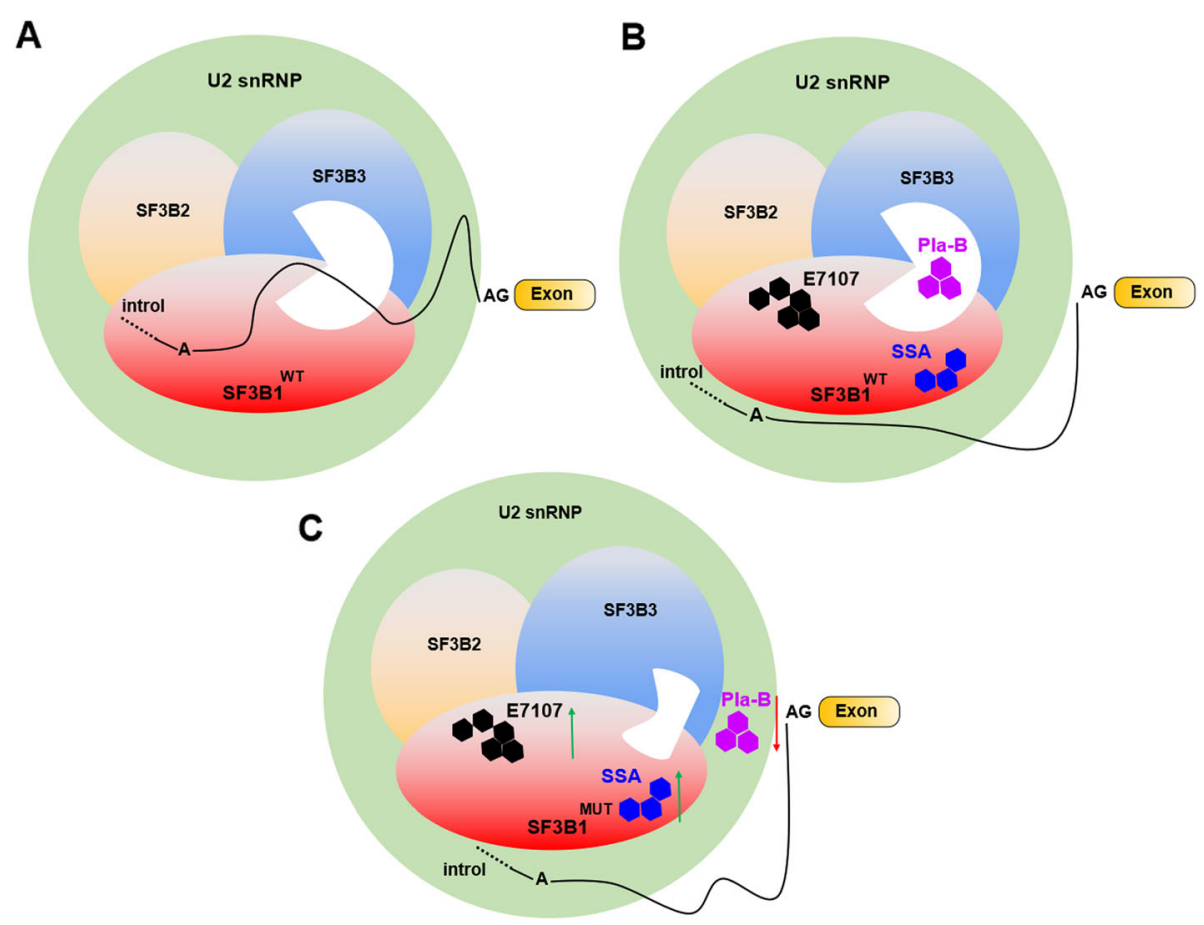

Fig. 5 Molecular effects of SF3B small-molecule inhibitors on 3' splice site recognition mediated by SF3B1 mutation. a: Normal condition of $3^{\prime}$ splice site recognition induced by SF3B1WT. b: Effects of inhibitors on $3^{\prime}$ splice site recognition induced by SF3B1WT. PlaB inhibits mRNA splicing by fitting into a space between SF3B1 and SF3B3; E7101 and SSA inhibit splicing by fitting into SF3B1. c: Effects of inhibitors on $3^{\prime}$ splice site recognition induced by SF3B1MUT. Mutations impair the binding of PlaB, E7101 or SSA to SF3B1 
Overall, mutated SF3B1 has been detected in hematological malignancies and solid tumors and has been proven to be related to patient prognosis, abnormal transcription, alternative splicing, and sensitivity to SF3B small-molecule inhibitors. However, only a few genes affected by SF3B1 mutation have been extensively studied to date, and the roles and mechanisms of these genes still need to be confirmed.

\section{SF3B1 or its mutation as a novel therapeutic target in cancer}

Primary tumors with SF3B1 mutations display alternative splicing in select key genes in cancer, including CLL, MDS, and uveal melanoma; this signature is conserved between cancer sites and is independent of the mutant amino acid [95], which implies that SF3B1 mutations may represent an important clinical significance in tumors. Indeed, SF3B1 is the most commonly mutated spliceosomal component gene in breast cancer, and mutations affecting this gene are significantly associated with ER-positive disease [67]. Moreover, SF3B1 mutant cell lines were found to be sensitive to the SF3B complex inhibitor spliceostatin A, and treatment resulted in perturbation of the splicing signature [67]. Thus, given the multiple roles in the pathogenesis of tumors and splicing events induced by SF3B1 mutations in cancer, as well as the potentially increased sensitivity of cancers to some SF3B small-molecule inhibitors, SF3B1 or its mutation may represent a prognostic biomarker and therapeutic target for cancer, and pharmacological modulation of splicing may represent an important therapeutic strategy [134]. For example, although SF3B1 mutations occur at a low frequency (1.1\%) in prostate cancer (PCa) [69], SF3B1 mRNA and protein levels are higher in tumor glands than in nontumor adjacent regions [135]. Notably, SF3B1 expression correlated positively with clinical and molecular features, including Gleason score and vascular and perineural invasion. Pharmacological blockade of SF3B1 with pladienolide-B reduced malignant features of $\mathrm{PCa}$ cells and modulated key signaling pathways, malignancy markers, and expression of oncogenic splicing variants AR-v7 and In1-ghrelin, spliceosome components and splicing factors as well as expression of EJC and SURF components and NMD factors [135]. That is, dysregulation of SF3B1 expression may be involved in the development, progression, and aggressiveness of $\mathrm{PCa}$, and SF3B1 might represent a new prognostic biomarker and therapeutic target in this devastating pathology. These results also indicate that SF3B1 inhibition leads to a decrease in the aggressiveness features of $\mathrm{PCa}$ cells through both direct and indirect mechanisms, possibly involving the modulation of different types of cellular stress processes. As SF3B1 variants exhibit an impaired response to pladienolide B [132], other inhibitors, such as E7107E and SSA, may have better antitumor activity for $\mathrm{PCa}$. The prognostic and therapeutic potential of SF3B1 in other types of cancer needs to be further studied.

\section{Conclusions and future perspectives}

In eukaryotes, the RNA splicing system, as essential cellular machinery, is critical for successful transcription through constitutive splicing and guarantees the functional diversity of protein products through alternative splicing. Thus, deregulation of this machinery causes severe developmental abnormalities [42, 92, 136]. Recent studies have shown that mutations in the RNA splicing machinery significantly affect the RNA splicing system by altering many splicing patterns associated with 3' splice sites, suggesting that aberrant splicing patterns induced by spliceosome mutations are directly linked to disease phenotypes [13]. SF3B1 is a shared core component of snRNPs both in major and minor spliceosomes and plays a critical role in the early and later stages of spliceosome assembly. SF3B1 mutations occur in many types of tumor and play an important role in the development and progression of cancer. However, the functional impact and mechanisms of the SF3B1 mutationderegulated splicing pattern on oncogenesis need to be better understood. In addition, although it has become clear that aberrant premRNA alternative splicing is a major contributor to cancer phenotypes, studies on the misregulation of alternative splicing induced by SF3B1 mutation in cancer have not kept pace with the latest data. Moreover, mutant SF3B1 may have a distinct function not only in the direct regulation of RNA splicing but also in the elongation and stability of DNA, which may be important for the acquisition of specific disease phenotypes [36]. Further work is also required to evaluate the molecular mechanism by which mutations in SF3B1 HEAT domains may influence the base-pairing potential of U2 snRNA [14]. Future clinical work is also needed to explore the relationship between SF3B1 mutations and mutations in other cancer-related genes, including those of other spliceosome-associated proteins, splicing regulatory factors, and transcriptional factors. Moreover, a valuable tool for dissecting the effects of SF3B1 mutations on the transformation, splicing, and functions of SF3B1 was established in a mouse model $[87,88]$, and investigation of the role of the yeast ortholog Hsh155 supports a novel mechanism in which SF3B1 helps to define the BS during premRNA splicing [137]. These findings are part of wide ongoing effort to generate genetically engineered model systems to study the biological and biochemical consequences of spliceosomal mutations in model systems as diverse as yeast, zebrafish, mouse, and human cells [138]. Finally, as the effects of splicing-modulation strategies targeting SF3B1 
mutations are currently unpredictable, laboratory, preclinical and clinical studies are required to understand the biological function and clinical significance of SF3B1 mutations in cancer.

\section{Abbreviations}

ABCB7: ATP-binding cassette subfamily B member 7; adRP: Autosomal dominant retinitis pigmentosa; ALS: Amyotrophic lateral sclerosis; BC: Breast cancer; BRD9: Homo sapiens bromodomain containing 9; BS: Branch site; CLL: Chronic myeloid leukemia; ENOSF1: Enolase superfamily member 1; ESE: Exonic splicing enhancer; ESS: Exonic splicing silencer; HSC: Hematopoietic stem cells; HSPC: Hematopoietic stem progenitor cell; hnRNP: Heterogeneous nuclear ribonucleoprotein; ISE: Intronic splicing enhancer; ISS: Intronic splicing silencer; KLF8: Kruppel-like transcription factor 8; MAP 3 K7: Mitogen-activated protein kinase kinase kinase 7;

MDS: Myelodysplastic syndrome; snRNA: Small nuclear RNA; snRNP: Small nuclear ribonucleoprotein; SRSF2: Serine/arginine-rich splicing factor 2; SF3B1: Splicing factor $3 \mathrm{~b}$ subunit 1; SURP1: SURP and G-Patch domain containing 1; TERC: Telomerase RNA component; TERT: Telomerase reverse transcriptase; TMEM14C: Transmembrane protein 14C; U2AF1: U2 small nuclear RNA auxiliary factor 1; UM: Uveal melanoma; ZRSR2: CCCH type zinc finger, RNA binding motif and serine/arginine rich protein 2

\section{Acknowledgments}

Not applicable.

\section{Authors' contributions}

All authors contributed to the literature search and writing of the manuscript. All authors read and approved the final manuscript.

\section{Funding}

This study was supported by the Qingdao Source Innovation Program (18-22-76-jch), the National Natural Science Foundation of China (91849209,

31671447), and the Innovative Talent Program of Qingdao (18-1-2-6-zhc).

\section{Availability of data and materials}

Not applicable, all information in this review can be found in the reference list.

\section{Ethics approval and consent to participate}

No ethics approval was required for this review that did not involve patients or patient data.

\section{Consent for publication}

All authors consent to publication.

\section{Competing interests}

The authors declare that they have no competing interests.

\section{Author details}

'Institute for Translational Medicine, The Affiliated Hospital of Qingdao University, College of Medicine, Qingdao University, Qingdao 266012, People's Republic of China. ${ }^{2}$ The Second Clinical Medical College of Qingdao University, Qingdao 266042, People's Republic of China.

\section{Received: 29 June 2020 Accepted: 24 August 2020}

Published online: 03 September 2020

\section{References}

1. Genomics PE. ENCODE project writes eulogy for junk DNA. Science. 2012; 337(6099):1159 1161.

2. Ezkurdia I, Juan D, Rodriguez JM, Frankish A, Diekhans M, Harrow J, Vazquez J, Valencia A, Tress ML. Multiple evidence strands suggest that there may be as few as 19,000 human protein-coding genes. Hum Mol Genet. 2014; 23(22):5866-78.

3. Kim MS, Pinto SM, Getnet D, Nirujogi RS, Manda SS, Chaerkady R, Madugundu AK, Kelkar DS, Isserlin R, Jain S, et al. A draft map of the human proteome. Nature. 2014;509(7502):575-81.
4. Wilhelm M, Schlegl J, Hahne H, Gholami AM, Lieberenz M, Savitski MM, Ziegler E, Butzmann L, Gessulat S, Marx H, et al. Mass-spectrometry-based draft of the human proteome. Nature. 2014;509(7502):582-7.

5. Singh RK, Cooper TA. Pre-mRNA splicing in disease and therapeutics. Trends Mol Med. 2012;18(8):472-82.

6. Scotti MM, Swanson MS. RNA mis-splicing in disease. Nat Rev Genet. 2016; 17(1):19-32

7. Padgett RA. New connections between splicing and human disease. Trends Genet. 2012;28(4):147-54

8. He C, Zhou F, Zuo Z, Cheng H, Zhou R. A global view of cancer-specific transcript variants by subtractive transcriptome-wide analysis. PLoS One. 2009:4(3):e4732.

9. Ogawa S. Splicing factor mutations in myelodysplasia. Int J Hematol. 2012; 96(4):438-42.

10. Maciejewski JP, Padgett RA. Defects in spliceosomal machinery: a new pathway of leukaemogenesis. Br J Haematol. 2012;158(2):165-73.

11. Makishima H, Visconte $V$, Sakaguchi H, Jankowska AM, Abu Kar S, Jerez A, Przychodzen B, Bupathi M, Guinta K, Afable MG, et al. Mutations in the spliceosome machinery, a novel and ubiquitous pathway in leukemogenesis. Blood. 2012;119(14):3203-10.

12. Auboeuf D, Carmo-Fonseca M, Valcarcel J, Biamonti G. Alternative splicing and cancer. J Nucleic Acids. 2012;2012:363809.

13. Lee $Y$, Rio DC. Mechanisms and regulation of alternative pre-mRNA splicing Annu Rev Biochem. 2015;84:291-323.

14. Alsafadi S, Houy A, Battistella A, Popova T, Wassef M, Henry E, Tirode F, Constantinou A, Piperno-Neumann S, Roman-Roman S, et al. Cancerassociated SF3B1 mutations affect alternative splicing by promoting alternative branchpoint usage. Nat Commun. 2016;7:10615.

15. Chen $\mathrm{HC}$, Cheng SC. Functional roles of protein splicing factors. Biosci Rep. 2012:32(4):345-59.

16. Wahl MC, Will CL, Luhrmann R. The spliceosome: design principles of a dynamic RNP machine. Cell. 2009:136(4):701-18.

17. Sahebi M, Hanafi MM, van Wijnen AJ, Azizi P, Abiri R, Ashkani S, Taheri S. Towards understanding pre-mRNA splicing mechanisms and the role of SR proteins. Gene. 2016;587(2):107-19.

18. Hall SL, Padgett RA. Requirement of U12 snRNA for in vivo splicing of a minor class of eukaryotic nuclear pre-mRNA introns. Science. 1996; 271(5256):1716-8.

19. Ishikawa H, Nobe Y, Izumikawa K, Taoka M, Yamauchi Y, Nakayama H, Simpson RJ, Isobe T, Takahash N. Truncated forms of U2 snRNA (U2-tfs) are shunted toward a novel uridylylation pathway that differs from the degradation pathway for U1-tfs. RNA Biol. 2018;15(2):261-8.

20. Tarn WY, Steitz JA. A novel spliceosome containing U11, U12, and U5 snRNPs excises a minor class (AT-AC) intron in vitro. Cell. 1996:84(5):801-11.

21. Moyer DC, Larue GE, Hershberger CE, Roy SW, Padgett RA. Comprehensive database and evolutionary dynamics of U12-type introns. Nucleic Acids Res. 2020:48(13):7066-78.

22. Dietrich RC, Incorvaia R, Padgett RA. Terminal intron dinucleotide sequences do not distinguish between U2- and U12-dependent introns. Mol Cell. 1997;1(1):151-60.

23. Will CL, Luhrmann R. Splicing of a rare class of introns by the U12dependent spliceosome. Biol Chem. 2005;386(8):713-24.

24. Hertel KJ. Spliceosomal pre-mRNA splicing : methods and protocols. New York: Humana Press ; Springer; 2014.

25. van der Feltz C, Hoskins AA. Structural and functional modularity of the U2 snRNP in pre-mRNA splicing. Crit Rev Biochem Mol Biol. 2019;54(5):443-65.

26. Zhou Z, Licklider $\sqcup$, Gygi SP, Reed R. Comprehensive proteomic analysis of the human spliceosome. Nature. 2002;419(6903):182-5.

27. Will CL, Schneider C, MacMillan AM, Katopodis NF, Neubauer G, Wilm M, Luhrmann R, Query CC. A novel U2 and U11/U12 snRNP protein that associates with the pre-mRNA branch site. EMBO J. 2001;20(16):4536-46.

28. Will CL, Schneider $\mathrm{C}$, Reed R, Luhrmann R. Identification of both shared and distinct proteins in the major and minor spliceosomes. Science. 1999; 284(5422):2003-5.

29. da Silva MR, Moreira GA, Goncalves da Silva RA, de Almeida Alves Barbosa E, Pais Siqueira R, Teixera RR, Almeida MR, Silva Junior A, Fietto JL, Bressan GC. Splicing Regulators and Their Roles in Cancer Biology and Therapy. Biomed Res Int. 2015;2015:150514.

30. Golas MM, Sander B, Will CL, Luhrmann R, Stark H. Major conformational change in the complex SF3b upon integration into the spliceosomal U11/ U12 di-snRNP as revealed by electron cryomicroscopy. Mol Cell. 2005;17(6): 869-83. 
31. Kramer A. The structure and function of proteins involved in mammalian pre-mRNA splicing. Annu Rev Biochem. 1996;65:367-409.

32. Graveley BR, Hertel KJ, Maniatis T. SR proteins are 'locators' of the RNA splicing machinery. Curr Biol. 1999;9(1):R6-7.

33. Comitato A, Spampanato C, Chakarova C, Sanges D, Bhattacharya SS, Marigo V. Mutations in splicing factor PRPF3, causing retinal degeneration, form detrimental aggregates in photoreceptor cells. Hum Mol Genet. 2007; 16(14):1699-707.

34. Tanackovic G, Ransijn A, Ayuso C, Harper S, Berson EL, Rivolta C. A missense mutation in PRPF6 causes impairment of pre-mRNA splicing and autosomal-dominant retinitis pigmentosa. Am J Hum Genet. 2011;88(5):6439.

35. van den Hoogenhof MM, Pinto YM, Creemers EE. RNA splicing: regulation and Dysregulation in the heart. Circ Res. 2016;118(3):454-68.

36. Zhang J, Manley JL. Misregulation of pre-mRNA alternative splicing in cancer. Cancer Discov. 2013;3(11):1228-37.

37. Wang ET, Sandberg R, Luo S, Khrebtukova I, Zhang L, Mayr C, Kingsmore SF, Schroth GP, Burge CB. Alternative isoform regulation in human tissue transcriptomes. Nature. 2008;456(7221):470-6.

38. Pan Q, Shai O, Lee $L J$, Frey BJ, Blencowe BJ. Deep surveying of alternative splicing complexity in the human transcriptome by high-throughput sequencing. Nat Genet. 2008;40(12):1413-5.

39. Leoni G, Le Pera L, Ferre F, Raimondo D, Tramontano A. Coding potential of the products of alternative splicing in human. Genome Biol. 2011;12(1):R9.

40. Bland CS, Wang ET, Vu A, David MP, Castle JC, Johnson JM, Burge CB, Cooper TA. Global regulation of alternative splicing during myogenic differentiation. Nucleic Acids Res. 2010;38(21):7651-64.

41. Cazzola M, Rossi M, Malcovati L. Associazione Italiana per la Ricerca sul Cancro Gruppo Italiano Malattie M. biologic and clinical significance of somatic mutations of SF3B1 in myeloid and lymphoid neoplasms. Blood. 2013;121(2):260-9.

42. Ebert $\mathrm{B}$, Bernard OA. Mutations in RNA splicing machinery in human cancers. N Engl J Med. 2011;365(26):2534-5.

43. Treisman R, Orkin SH, Maniatis T. Specific transcription and RNA splicing defects in five cloned beta-thalassaemia genes. Nature. 1983;302(5909):5916.

44. Treisman R, Proudfoot NJ, Shander M, Maniatis T. A single-base change at a splice site in a beta 0-thalassemic gene causes abnormal RNA splicing. Cell. 1982;29(3):903-11.

45. Kim HJ, Kim NC, Wang YD, Scarborough EA, Moore J, Diaz Z, MacLea KS, Freibaum B, Li S, Molliex A, et al. Mutations in prion-like domains in hnRNPA2B1 and hnRNPA1 cause multisystem proteinopathy and ALS. Nature. 2013;495(7442):467-73.

46. Le Ber I, Van Bortel I, Nicolas G, Bouya-Ahmed K, Camuzat A, Wallon D, De Septenville A, Latouche M, Lattante S, Kabashi E, et al. hnRNPA2B1 and hnRNPA1 mutations are rare in patients with "multisystem proteinopathy" and frontotemporal lobar degeneration phenotypes. Neurobiol Aging. 2014; 35(4):934 e935-6.

47. Srebrow A, Kornblihtt AR. The connection between splicing and cancer. J Cell Sci. 2006;119(Pt 13):2635-41.

48. Sveen A, Kilpinen S, Ruusulehto A, Lothe RA, Skotheim RI. Aberrant RNA splicing in cancer; expression changes and driver mutations of splicing factor genes. Oncogene. 2016;35(19):2413-27.

49. Will CL, Luhrmann R. Spliceosome structure and function. Cold Spring Harb Perspect Biol. 2011;3(7):a003707

50. Thickman KR, Swenson MC, Kabogo JM, Gryczynski Z, Kielkopf CL. Multiple U2AF65 binding sites within SF3b155: thermodynamic and spectroscopic characterization of protein-protein interactions among pre-mRNA splicing factors. J Mol Biol. 2006;356(3):664-83.

51. Thickman KR, Sickmier EA, Kielkopf CL. Alternative conformations at the RNA-binding surface of the N-terminal U2AF(65) RNA recognition motif. J Mol Biol. 2007;366(3):703-10.

52. Cretu C, Schmitzova J, Ponce-Salvatierra A, Dybkov O, De Laurentiis El, Sharma K, Will CL, Urlaub H, Luhrmann R, Pena V. Molecular architecture of SF3b and structural consequences of its Cancer-related mutations. Mol Cell. 2016;64(2):307-19.

53. Zhang J, Ali AM, Lieu YK, Liu Z, Gao J, Rabadan R, Raza A, Mukherjee S, Manley JL. Disease-causing mutations in SF3B1 Alter splicing by disrupting interaction with SUGP1. Mol Cell. 2019;76(1):82-95 e87.

54. Dalton WB, Helmenstine E, Pieterse L, Li B, Gocke CD, Donaldson J, Xiao Z, Gondek LP, Ghiaur G, Gojo I, et al. The K666N mutation in SF3B1 is associated with increased progression of MDS and distinct RNA splicing. Blood Adv. 2020:4(7):1192-6.

55. Samy A, Suzek BE, Ozdemir MK, Sensoy O. In Silico Analysis of a Highly Mutated Gene in Cancer Provides Insight into Abnormal mRNA Splicing: Splicing Factor 3B Subunit 1(K700E) Mutant. Biomolecules. 2020;10(5):680.

56. Song J, Hussaini M, Qin D, Zhang X, Shao H, Zhang L, Gajzer D, Basra P, Moscinski L, Zhang H. Comparison of SF3B1/DNMT3A Comutations with DNMT3A or SF3B1 mutation alone in Myelodysplastic syndrome and clonal Cytopenia of undetermined significance. Am J Clin Pathol. 2020;154(1):4856.

57. Bergot T, Lippert E, Douet-Guilbert N, Commet S, Corcos L, Bernard DG. Human Cancer-Associated Mutations of SF3B1 Lead to a Splicing Modification of Its Own RNA. Cancers (Basel). 2020;12(3):652.

58. Scott LM, Rebel VI. Acquired mutations that affect pre-mRNA splicing in hematologic malignancies and solid tumors. J Natl Cancer Inst. 2013; 105(20):1540-9.

59. Foy A, McMullin MF. Somatic SF3B1 mutations in myelodysplastic syndrome with ring sideroblasts and chronic lymphocytic leukaemia. J Clin Pathol. 2019;72(11):778-82.

60. Tang AD, Soulette CM, van Baren MJ, Hart K, Hrabeta-Robinson E, Wu CJ, Brooks AN. Full-length transcript characterization of SF3B1 mutation in chronic lymphocytic leukemia reveals downregulation of retained introns. Nat Commun. 2020;11(1):1438.

61. Ellis MJ, Ding L, Shen D, Luo J, Suman VJ, Wallis JW, Van Tine BA, Hoog J, Goiffon RJ, Goldstein TC, et al. Whole-genome analysis informs breast cancer response to aromatase inhibition. Nature. 2012;486(7403):353-60.

62. Hou C, Xiao L, Ren X, Tang F, Guo B, Zeng W, Liang C, Yan N. Mutations of GNAQ, GNA11, SF3B1, EIF1AX, PLCB4 and CYSLTR in Uveal melanoma in Chinese patients. Ophthalmic Res. 2020;63(3):358-68.

63. Stephens PJ, Tarpey PS, Davies H, Van Loo P, Greenman C, Wedge DC, NikZainal S, Martin S, Varela I, Bignell GR, et al. The landscape of cancer genes and mutational processes in breast cancer. Nature. 2012;486(7403):400-4.

64. Kusters-Vandevelde HV, Creytens D, van Engen-van Grunsven AC, Jeunink M, Winnepenninckx V, Groenen PJ, Kusters B, Wesseling P, Blokx WA, Prinsen CF. SF3B1 and EIF1AX mutations occur in primary leptomeningeal melanocytic neoplasms; yet another similarity to uveal melanomas. Acta Neuropathol Commun. 2016;4:5.

65. Kong Y, Krauthammer M, Halaban R. Rare SF3B1 R625 mutations in cutaneous melanoma. Melanoma Res. 2014;24(4):332-4.

66. Molenaar JJ, Koster J, Zwijnenburg DA, van Sluis P, Valentijn $L J$, van der Ploeg I, Hamdi M, van Nes J, Westerman BA, van Arkel J, et al. Sequencing of neuroblastoma identifies chromothripsis and defects in neuritogenesis genes. Nature. 2012;483(7391):589-93.

67. Banerji S, Cibulskis K, Rangel-Escareno C, Brown KK, Carter SL, Frederick AM, Lawrence MS, Sivachenko AY, Sougnez C, Zou L, et al. Sequence analysis of mutations and translocations across breast cancer subtypes. Nature. 2012; 486(7403):405-9.

68. Biankin AV, Waddell N, Kassahn KS, Gingras MC, Muthuswamy LB, Johns AL, Miller DK, Wilson PJ, Patch AM, Wu J, et al. Pancreatic cancer genomes reveal aberrations in axon guidance pathway genes. Nature. 2012;491(7424): 399-405.

69. Armenia J, Wankowicz SAM, Liu D, Gao J, Kundra R, Reznik E, Chatila WK, Chakravarty D, Han GC, Coleman I, et al. The long tail of oncogenic drivers in prostate cancer. Nat Genet. 2018;50(5):645-51.

70. Li C, Xie W, Rosenblum JS, Zhou J, Guo J, Miao Y, Shen Y, Wang H, Gong L, Li M, et al. Somatic SF3B1 hotspot mutation in prolactinomas. Nat Commun. 2020;11(1):2506.

71. Yu J, Li Y, Zhang D, Wan D, Jiang Z. Clinical implications of recurrent gene mutations in acute myeloid leukemia. Exp Hematol Oncol. 2020;9:4.

72. Yu J, Li Y, Li T, Li Y, Xing H, Sun H, Sun L, Wan D, Liu Y, Xie X, et al. Gene mutational analysis by NGS and its clinical significance in patients with myelodysplastic syndrome and acute myeloid leukemia. Exp Hematol Oncol. 2020;9:2.

73. Rose AM, Luo R, Radia UK, Kalirai H, Thornton S, Luthert PJ, Jayasena CN, Verity DH, Coupland SE, Rose GE. Detection of mutations in SF3B1, EIF1AX and GNAQ in primary orbital melanoma by candidate gene analysis. BMC Cancer. 2018;18(1):1262.

74. Seiler M, Peng S, Agrawal AA, Palacino J, Teng T, Zhu P, Smith PG. Cancer genome atlas research N, Buonamici S, Yu L. somatic mutational landscape of splicing factor genes and their functional consequences across 33 Cancer types. Cell Rep. 2018;23(1):282-96 e284. 
75. Je EM, Yoo NJ, Kim YJ, Kim MS, Lee SH. Mutational analysis of splicing machinery genes SF3B1, U2AF1 and SRSF2 in myelodysplasia and other common tumors. Int J Cancer. 2013;133(1):260-5.

76. Seo JY, Lee KO, Kim SH, Kim K, Jung CW, Jang JH, Kim HJ. Clinical significance of SF3B1 mutations in Korean patients with myelodysplastic syndromes and myelodysplasia/myeloproliferative neoplasms with ring sideroblasts. Ann Hematol. 2014;93(4):603-8.

77. Patnaik MM, Lasho TL, Hodnefield JM, Knudson RA, Ketterling RP, GarciaManero G, Steensma DP, Pardanani A, Hanson CA, Tefferi A. SF3B1 mutations are prevalent in myelodysplastic syndromes with ring sideroblasts but do not hold independent prognostic value. Blood. 2012 119(2):569-72.

78. Damm F, Kosmider O, Gelsi-Boyer V, Renneville A, Carbuccia N, HidalgoCurtis C, Della Valle V, Couronne L, Scourzic L, Chesnais V, et al. Mutations affecting mRNA splicing define distinct clinical phenotypes and correlate with patient outcome in myelodysplastic syndromes. Blood. 2012;119(14): 3211-8.

79. Thol F, Kade S, Schlarmann C, Loffeld P, Morgan M, Krauter J, Wlodarski MW Kolking B, Wichmann M, Gorlich K, et al. Frequency and prognostic impact of mutations in SRSF2, U2AF1, and ZRSR2 in patients with myelodysplastic syndromes. Blood. 2012;119(15):3578-84.

80. Hosono N. Genetic abnormalities and pathophysiology of MDS. Int J Clin Oncol. 2019;24(8):885-92.

81. Harbour JW, Roberson ED, Anbunathan H, Onken MD, Worley LA, Bowcock AM. Recurrent mutations at codon 625 of the splicing factor SF3B1 in uveal melanoma. Nat Genet. 2013;45(2):133-5.

82. Quek C, Rawson RV, Ferguson PM, Shang P, Silva I, Saw RPM, Shannon K, Thompson JF, Hayward NK, Long GV, et al. Recurrent hotspot SF3B1 mutations at codon 625 in vulvovaginal mucosal melanoma identified in a study of 27 Australian mucosal melanomas. Oncotarget. 2019;10(9):930-41.

83. Yavuzyigitoglu S, Koopmans AE, Verdijk RM, Vaarwater J, Eussen B, van Bodegom A, Paridaens D, Kilic E, de Klein A. Rotterdam ocular melanoma study G. Uveal melanomas with SF3B1 mutations: a distinct subclass associated with late-onset metastases. Ophthalmology. 2016;123(5):1118-28.

84. Zhou Q, Derti A, Ruddy D, Rakiec D, Kao I, Lira M, Gibaja V, Chan H, Yang Y, Min J, et al. A chemical genetics approach for the functional assessment of novel cancer genes. Cancer Res. 2015;75(10):1949-58.

85. Obeng EA, Chappell RJ, Seiler M, Chen MC, Campagna DR, Schmidt PJ, Schneider RK, Lord AM, Wang L, Gambe RG, et al. Physiologic expression of Sf3b1(K700E) causes impaired erythropoiesis, aberrant splicing, and sensitivity to therapeutic Spliceosome modulation. Cancer Cell. 2016;30(3): 404-17.

86. Mupo A, Seiler M, Sathiaseelan V, Pance A, Yang Y, Agrawal AA, lorio F, Bautista R, Pacharne S, Tzelepis K, et al. Hemopoietic-specific Sf3b1-K700E knock-in mice display the splicing defect seen in human MDS but develop anemia without ring sideroblasts. Leukemia. 2017;31(3):720-7.

87. Papaemmanuil E, Gerstung M, Malcovati L, Tauro S, Gundem G, Van Loo P, Yoon CJ, Ellis P, Wedge DC, Pellagatti A, et al. Clinical and biological implications of driver mutations in myelodysplastic syndromes. Blood. 2013; 122(22):3616-27 quiz 3699.

88. Haferlach T, Nagata Y, Grossmann V, Okuno Y, Bacher U, Nagae G, Schnittger S, Sanada M, Kon A, Alpermann T, et al. Landscape of genetic lesions in 944 patients with myelodysplastic syndromes. Leukemia. 2014; 28(2):241-7.

89. Lee SC, North K, Kim E, Jang E, Obeng E, Lu SX, Liu B, Inoue D, Yoshimi A, Ki M, et al. Synthetic lethal and convergent biological effects of Cancer-associated Spliceosomal gene mutations. Cancer Cell. 2018;34(2):225-41 e228.

90. Te Raa GD, Derks IA, Navrkalova V, Skowronska A, Moerland PD, van Laar J, Oldreive C, Monsuur H, Trbusek M, Malcikova J, et al. The impact of SF3B1 mutations in CLL on the DNA-damage response. Leukemia. 2015;29(5): $1133-42$.

91. Wang L, Brooks AN, Fan J, Wan Y, Gambe R, Li S, Hergert S, Yin S, Freeman SS, Levin JZ, et al. Transcriptomic characterization of SF3B1 mutation reveals its pleiotropic effects in chronic lymphocytic leukemia. Cancer Cell. 2016; 30(5):750-63.

92. Pellagatti A, Armstrong RN, Steeples V, Sharma E, Repapi E, Singh S, Sanchi A, Radujkovic A, Horn P, Dolatshad H, et al. Impact of spliceosome mutations on RNA splicing in myelodysplasia: dysregulated genes/pathways and clinical associations. Blood. 2018;132(12):1225-40.

93. Singh S, Ahmed D, Dolatshad H, Tatwavedi D, Schulze U, Sanchi A, Ryley S, Dhir A, Carpenter L, Watt SM, et al. SF3B1 mutations induce R-loop accumulation and DNA damage in MDS and leukemia cells with therapeutic implications. Leukemia. 2020;34(9):2525-30.

94. Darman RB, Seiler M, Agrawal AA, Lim KH, Peng S, Aird D, Bailey SL, Bhavsar EB, Chan B, Colla S, et al. Cancer-associated SF3B1 hotspot mutations induce cryptic $3^{\prime}$ splice site selection through use of a different branch point. Cell Rep. 2015;13(5):1033-45.

95. Gentien D, Kosmider O, Nguyen-Khac F, Albaud B, Rapinat A, Dumont AG, Damm F, Popova T, Marais R, Fontenay M, et al. A common alternative splicing signature is associated with SF3B1 mutations in malignancies from different cell lineages. Leukemia. 2014;28(6):1355-7.

96. Dolatshad H, Pellagatti A, Liberante FG, Llorian M, Repapi E, Steeples V, Roy S, Scifo L, Armstrong RN, Shaw J, et al. Cryptic splicing events in the iron transporter ABCB7 and other key target genes in SF3B1-mutant myelodysplastic syndromes. Leukemia. 2016;30(12):2322-31.

97. Furney SJ, Pedersen M, Gentien D, Dumont AG, Rapinat A, Desjardins L, Turajlic S, Piperno-Neumann S, de la Grange P, Roman-Roman S, et al. SF3B1 mutations are associated with alternative splicing in uveal melanoma. Cancer Discov. 2013;3(10):1122-9.

98. Liu Z, Yoshimi A, Wang J, Cho H, Chun-Wei Lee S, Ki M, Bitner L, Chu T, Shah $\mathrm{H}$, Liu B, et al. Mutations in the RNA splicing factor SF3B1 promote tumorigenesis through MYC stabilization. Cancer Discov. 2020;10(6):806-21.

99. Jafari PA, Sadeghian MH, Miri HH, Sadeghi R, Bagheri R, Lavasani S, Souri S. Prognostic significance of SF3B1 mutations in patients with myelodysplastic syndromes: a meta-analysis. Crit Rev Oncol Hematol. 2020;145:102832.

100. Gatchalian J, Malik S, Ho J, Lee DS, Kelso TWR, Shokhirev MN, Dixon JR, Hargreaves DC. A non-canonical BRD9-containing BAF chromatin remodeling complex regulates naive pluripotency in mouse embryonic stem cells. Nat Commun. 2018;9(1):5139.

101. Michel BC, D'Avino AR, Cassel SH, Mashtalir N, McKenzie ZM, McBride MJ, Valencia AM, Zhou Q, Bocker M, Soares LMM, et al. A non-canonical SWI/ SNF complex is a synthetic lethal target in cancers driven by BAF complex perturbation. Nat Cell Biol. 2018;20(12):1410-20.

102. Hohmann AF, Martin LJ, Minder JL, Roe JS, Shi J, Steurer S, Bader G, McConnell D, Pearson M, Gerstberger T, et al. Sensitivity and engineered resistance of myeloid leukemia cells to BRD9 inhibition. Nat Chem Biol. 2016;12(9):672-9.

103. Brien GL, Remillard D, Shi J, Hemming ML, Chabon J, Wynne K, Dillon ET, Cagney G, Van Mierlo G, Baltissen MP, et al. Targeted degradation of BRD9 reverses oncogenic gene expression in synovial sarcoma. Elife. 2018;7.

104. Inoue D, Chew GL, Liu B, Michel BC, Pangallo J, D'Avino AR, Hitchman T, North K, Lee SC, Bitner L, et al. Spliceosomal disruption of the non-canonical BAF complex in cancer. Nature. 2019;574(7778):432-6.

105. Crisci A, Raleff F, Bagdiul I, Raabe M, Urlaub H, Rain JC, Kramer A. Mammalian splicing factor SF1 interacts with SURP domains of U2 snRNPassociated proteins. Nucleic Acids Res. 2015;43(21):10456-73.

106. Robert-Paganin J, Rety S, Leulliot N. Regulation of DEAH/RHA helicases by G-patch proteins. Biomed Res Int. 2015;2015:931857.

107. Liu Z, Zhang J, Sun Y, Perea-Chamblee TE, Manley JL, Rabadan R. Pan-cancer analysis identifies mutations in SUGP1 that recapitulate mutant SF3B1 splicing dysregulation. Proc Natl Acad Sci U S A. 2020;117(19):10305-12.

108. Cancer-Linked SF3B1 Mutations Cause Faulty Splicing and SUGP1 Binding. Cancer Discov. 2019;9(10):1336. https://doi.org/10.1158/2159-8290.cdrw2019-138

109. Ajibade AA, Wang Q, Cui J, Zou J, Xia X, Wang M, Tong Y, Hui W, Liu D, Su $B$, et al. TAK1 negatively regulates NF-kappaB and p38 MAP kinase activation in gr-1+CD11b+ neutrophils. Immunity. 2012;36(1):43-54

110. Santoro R, Carbone C, Piro G, Chiao PJ, Melisi D. TAK-ing aim at chemoresistance: the emerging role of MAP 3K7 as a target for cancer therapy. Drug Resist Updat. 2017;33-35:36-42.

111. Rajasekaran K, Kumar P, Schuldt KM, Peterson EJ, Vanhaesebroeck B, Dixit V, Thakar MS, Malarkannan S. Signaling by Fyn-ADAP via the Carma1-BCl-10MAP 3K7 signalosome exclusively regulates inflammatory cytokine production in NK cells. Nat Immunol. 2013;14(11):1127-36.

112. Marrone A, Stevens D, Vulliamy T, Dokal I, Mason PJ. Heterozygous telomerase RNA mutations found in dyskeratosis congenita and aplastic anemia reduce telomerase activity via haploinsufficiency. Blood. 2004; 104(13):3936-42.

113. Yamaguchi H, Baerlocher GM, Lansdorp PM, Chanock SJ, Nunez O, Sloand E, Young NS. Mutations of the human telomerase RNA gene (TERC) in aplastic anemia and myelodysplastic syndrome. Blood. 2003;102(3):916-8. 
114. Heselmeyer-Haddad K, Sommerfeld K, White NM, Chaudhri N, Morrison LE, Palanisamy N, Wang ZY, Auer G, Steinberg W, Ried T. Genomic amplification of the human telomerase gene (TERC) in pap smears predicts the development of cervical cancer. Am J Pathol. 2005;166(4):1229-38.

115. Liu H, Liu S, Wang H, Xie X, Chen X, Zhang X, Zhang Y. Genomic amplification of the human telomerase gene (hTERC) associated with human papillomavirus is related to the progression of uterine cervical dysplasia to invasive cancer. Diagn Pathol. 2012;7:147.

116. Taggart AJ, DeSimone AM, Shih JS, Filloux ME, Fairbrother WG. Large-scale mapping of branchpoints in human pre-mRNA transcripts in vivo. Nat Struct Mol Biol. 2012;19(7):719-21.

117. Collu GM, Hidalgo-Sastre A, Acar A, Bayston L, Gildea C, Leverentz MK, Mills CG, Owens TW, Meurette O, Dorey K, et al. Dishevelled limits notch signalling through inhibition of CSL. Development. 2012;139(23):4405-15.

118. Tauriello DV, Jordens I, Kirchner K, Slootstra JW, Kruitwagen T, Bouwman BA, Noutsou M, Rudiger SG, Schwamborn K, Schambony A, et al. Wnt/betacatenin signaling requires interaction of the Dishevelled DEP domain and $C$ terminus with a discontinuous motif in frizzled. Proc Natl Acad Sci U S A. 2012;109(14):E812-20.

119. Spiliotis ET, Kinoshita M, Nelson WJ. A mitotic septin scaffold required for mammalian chromosome congression and segregation. Science. 2005; 307(5716):1781-5.

120. Cao LQ, Shao ZL, Liang HH, Zhang DW, Yang XW, Jiang XF, Xue P. Activation of peroxisome proliferator-activated receptor-gamma (PPARgamma) inhibits hepatoma cell growth via downregulation of SEPT2 expression. Cancer Lett. 2015;359(1):127-35.

121. Boultwood J, Pellagatti A, Nikpour M, Pushkaran B, Fidler C, Cattan H, Littlewood TJ, Malcovati L, Della Porta MG, Jadersten M, et al. The role of the iron transporter $A B C B 7$ in refractory anemia with ring sideroblasts. PLOS One. 2008;3(4):e1970.

122. Pondarre C, Campagna DR, Antiochos B, Sikorski L, Mulhern H, Fleming MD. Abcb7, the gene responsible for $\mathrm{X}$-linked sideroblastic anemia with ataxia, is essential for hematopoiesis. Blood. 2007;109(8):3567-9.

123. Cavadini P, Biasiotto G, Poli M, Levi S, Verardi R, Zanella I, Derosas M, Ingrassia R, Corrado M, Arosio P. RNA silencing of the mitochondrial ABCB7 transporter in HeLa cells causes an iron-deficient phenotype with mitochondrial iron overload. Blood. 2007;109(8):3552-9.

124. Nikpour M, Scharenberg C, Liu A, Conte S, Karimi M, Mortera-Blanco T, Giai V, Fernandez-Mercado M, Papaemmanuil E, Hogstrand K, et al. The transporter $A B C B 7$ is a mediator of the phenotype of acquired refractory anemia with ring sideroblasts. Leukemia. 2013;27(4):889-96.

125. Kaida D, Motoyoshi H, Tashiro E, Nojima T, Hagiwara M, Ishigami K, Watanabe $H$, Kitahara T, Yoshida T, Nakajima H, et al. Spliceostatin a targets SF3b and inhibits both splicing and nuclear retention of pre-mRNA. Nat Chem Biol. 2007:3(9):576-83.

126. Bonnal S, Vigevani L, Valcarcel J. The spliceosome as a target of novel antitumour drugs. Nat Rev Drug Discov. 2012;11(11):847-59.

127. Webb TR, Joyner AS, Potter PM. The development and application of small molecule modulators of SF3b as therapeutic agents for cancer. Drug Discov Today. 2013;18(1-2):43-9.

128. Effenberger KA, Urabe VK, Prichard BE, Ghosh AK, Jurica MS. Interchangeable SF3B1 inhibitors interfere with pre-mRNA splicing at multiple stages. RNA. 2016;22(3):350-9.

129. Cretu C, Agrawal AA, Cook A, Will CL, Fekkes P, Smith PG, Luhrmann R, Larsen N, Buonamici S, Pena V. Structural basis of splicing modulation by antitumor macrolide compounds. Mol Cell. 2018;70(2):265-73 e268.

130. Kotake $Y$, Sagane K, Owa T, Mimori-Kiyosue $Y$, Shimizu H, Uesugi M, Ishihama Y, Iwata M, Mizui Y. Splicing factor SF3b as a target of the antitumor natural product pladienolide. Nat Chem Biol. 2007:3(9):570-5.

131. Folco EG, Coil KE, Reed R. The anti-tumor drug E7107 reveals an essential role for SF3b in remodeling U2 SnRNP to expose the branch point-binding region. Genes Dev. 2011;25(5):440-4.

132. Yokoi A, Kotake $Y$, Takahashi $K$, Kadowaki T, Matsumoto $Y$, Minoshima $Y$, Sugi NH, Sagane K, Hamaguchi M, Iwata M, et al. Biological validation that SF3b is a target of the antitumor macrolide pladienolide. FEBS J. 2011 278(24):4870-80.

133. Maguire SL, Leonidou A, Wai P, Marchio C, Ng CK, Sapino A, Salomon AV, Reis-Filho JS, Weigelt B, Natrajan RC. SF3B1 mutations constitute a novel therapeutic target in breast cancer. J Pathol. 2015;235(4):571-80.

134. Dvinge $H$, Kim E, Abdel-Wahab O, Bradley RK. RNA splicing factors as oncoproteins and tumour suppressors. Nat Rev Cancer. 2016;16(7):413-30.
135. Jimenez-Vacas JM, Herrero-Aguayo V, Gomez-Gomez E, Leon-Gonzalez AJ, Saez-Martinez P, Alors-Perez E, Fuentes-Fayos AC, Martinez-Lopez A, Sanchez-Sanchez R, Gonzalez-Serrano T, et al. Spliceosome component SF3B1 as novel prognostic biomarker and therapeutic target for prostate cancer. Transl Res. 2019;212:89-103.

136. Zhou J, Chng WJ. Aberrant RNA splicing and mutations in spliceosome complex in acute myeloid leukemia. Stem Cell Investig. 2017;4:6.

137. Carrocci TJ, Zoerner DM, Paulson JC, Hoskins AA. SF3b1 mutations associated with myelodysplastic syndromes alter the fidelity of branchsite selection in yeast. Nucleic Acids Res. 2017:45(8):4837-52.

138. Inoue D, Abdel-Wahab O. Modeling SF3B1 mutations in Cancer: advances, challenges, and opportunities. Cancer Cell. 2016;30(3):371-3.

\section{Publisher's Note}

Springer Nature remains neutral with regard to jurisdictional claims in published maps and institutional affiliations.
Ready to submit your research? Choose BMC and benefit from:

- fast, convenient online submission

- thorough peer review by experienced researchers in your field

- rapid publication on acceptance

- support for research data, including large and complex data types

- gold Open Access which fosters wider collaboration and increased citations

- maximum visibility for your research: over $100 \mathrm{M}$ website views per year

At BMC, research is always in progress.

Learn more biomedcentral.com/submissions 